\title{
Polar Frontal Zone of the Barents Sea Western Trough Based on the Direct Measurements in 2007
}

\author{
A.N. Morozov ${ }^{1, *}$, V.K. Pavlov ${ }^{2}$, O.A. Pavlova ${ }^{2}$, S.V. Fedorov ${ }^{1}$ \\ ${ }^{1}$ Marine Hydrophysical Institute, Russian Academy of Sciences, Sevastopol, Russian Federation \\ *e-mail: anmorozov@mhi-ras.ru \\ ${ }^{2}$ Norwegian Polar Institute, Tromsø, Norway
}

\begin{abstract}
The results of measurements carried out in summer, 2007 in the north-western part of the Barents Sea are discussed. The ship weather station and the vessel mounted Acoustic Doppler current profiler VMADCP150 are used to carry out measurements in the vessel motion. CTD/LADCP-sensing is performed at the drift stations. The minimum horizontal scale of a temperature front is $0.5 \mathrm{~km}$, whereas the maximum horizontal gradient of water temperature is $4{ }^{\circ} \mathrm{C} / \mathrm{km}$. The width of the North Cape Current Northern branch is $\sim 8 \mathrm{~km}$ that is three times larger than the Rossby radius of deformation. Position of the temperature front coincides with that of the jet stream core. The characteristics of small-scale vertical structure of water dynamics and density stratification in the polar frontal zone are discussed. The averaged annual variability of temperature and salinity vertical structure in the area of the Spitsbergen Bank and the Hopen Deep are represented. The intra-annual variability of water salinity in the Hopen Deep calculated based on the historical database of hydrological data, revealed the presence of variations with a period of four months. Based on satellite observations, position of the temperature front in the area of research is defined.
\end{abstract}

Keywords: polar frontal zone, Spitsnbergen Bank, the Hopen Deep, Western trough of the Barents Sea, the North Cape Current Northern branch, $A D C P$.

DOI: 10.22449/1573-160X-2017-2-36-50

(c) 2017, A.N. Morozov, V.K. Pavlov, O.A. Pavlova, S.V. Fedorov

(C) 2017, Physical Oceanography

Introduction. Frontal zones separating waters different in their properties are observed in many parts of the World Ocean and have significant regional differences due to the physical nature of their formation [1]. In recent decades, the emphasis of experimental research is keeping to shift more and more to the polar regions, particularly to the Arctic, where the interannual signal manifestation is wellpronounced. At the same time, the polar frontal zones (PFZ) remain in the attention focus of scientists as the brightest indicator of the observed climatic changes and their influence on various components of the ecosystem [2].

The development of the contact oceanographic measuring technique at the present stage makes it possible to carry out studies of frontal zones in greater detail. Also, combining with historical and satellite observation data, it allows to reveal new small-scale structural features and regularities of the frontal zones. On the one hand, such measurements are aimed to provide specialists engaged in marine research with in situ material on the current state of the aquatic environment in the observation area; on the other hand - to enable specialists involved in simulation to assess the quality of the results of numerical experiments and the correctness of the choice of adjustable parameters.

During the International Polar Year (2007 - 2008) a number of multidisciplinary expeditions was conducted in the northwestern part of the Barents Sea. The purpose of this paper is to present and discuss the results of hydrophysical measurements carried out near the frontal zone of Western trough of the Barents Sea (the geo- 
graphical name is taken from [2]) within the framework of the project NESSAR 2007 - 2009 (Norwegian component of the Ecosystem Studies of Subarctic and Arctic Regions) supported by The Research Council of Norway (RCN).

The expedition took place on May 29 - June 10, 2007 in the region of the Hopen Deep and Spitsnbergen Bank (the geographical names are taken from [3]) on board of R/V Lance of the Norwegian Polar Institute, Tromsø. The scheme of measurements is shown in Fig. 1. On the latitudinal sections ( $L S x x, x x$ is the section number chronologically), the distance between the hydrological stations was about $62 \mathrm{~km}$ longitudinally, the distance between the stations in the micropolygon (MP) was about $12 \mathrm{~km}$ longitudinally and about $18 \mathrm{~km}$ latitudinally. At the diurnal station (DS), measurements were carried out every hour. The points A and B are located on opposite sides of the thermal front and are selected to calculate the mean annual temperature and salinity cycle under the BarKode hydrological database [4].

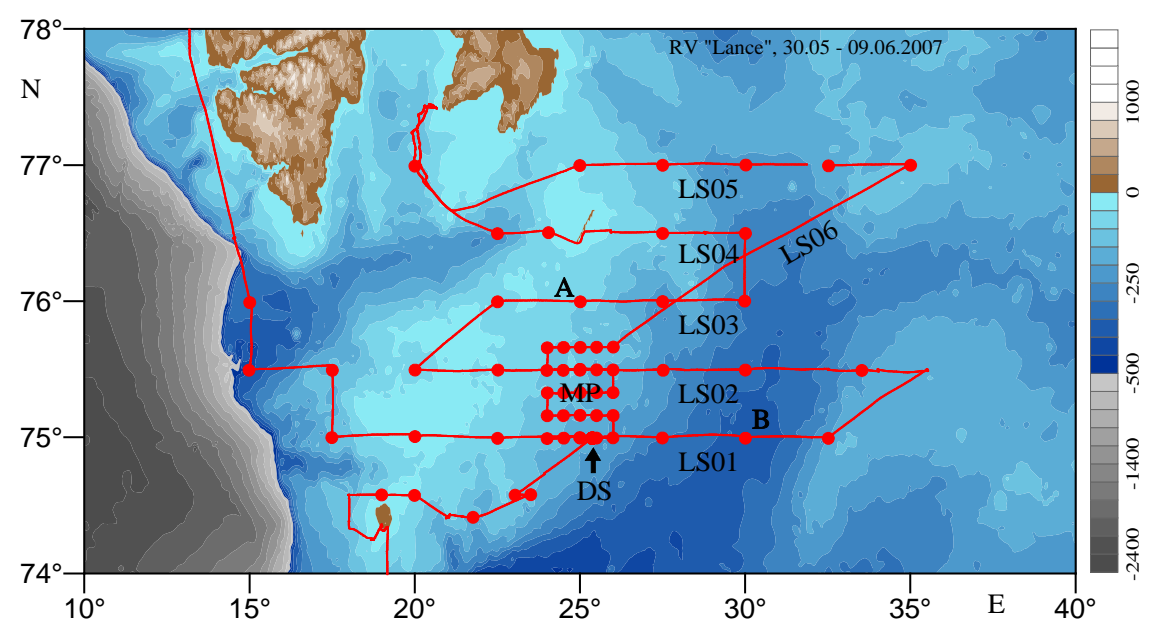

Fig. 1. Plan of the expedition. Red line marks the track of the vessel; red dots are the hydrological stations; $L S x x$ is the latitudinal section; $M P$ is the micropolygon; $D S$ is the diurnal station (the location is indicated by an arrow); $A$ and $B$ mark the points for calculating the annual course of temperature and salinity

Instruments. $\mathrm{R} / \mathrm{V}$ Lance is equipped by a shipboard weather station, the parameters measured are air temperature, atmospheric pressure, wind velocity and direction, water temperature in the near-surface layer of the sea and geographical coordinates (UTC). The measurements were carried out throughout the entire expedition with a discreteness of $1 \mathrm{~s}$. Also, the ship is equipped with the Acoustic Doppler current profiler VMADCP150 manufactured by RDI. The instrument settings were as follows: the depth segment size is $8 \mathrm{~m}$, the number of segments is 32 , the bottom tracking option (BT) is turned on to a depth of $400 \mathrm{~m}$, the discreteness of the measurement is $2 \mathrm{~s}$. The measurement layer was $20 \mathrm{~m}$ on the average from the sea surface to a depth of $150 \mathrm{~m}$ or up to $15 \mathrm{~m}$ above the bottom. The VMADCP data processing was carried out taking into account the problematic points considered in [5 - 7]. 
At the drift stations, the hydrological parameters were measured applying SeaBird SBE9+CTD-probe. Data on temperature $\left(T,{ }^{\circ} \mathrm{C}\right)$, salinity $(S, p s u)$, conditional density $\left(\sigma_{\theta}, \mathrm{kg} / \mathrm{m}^{3}\right)$ were interpolated onto the grid with $1 \mathrm{~m}$ depth step. To profile the current velocity on the SBE frame, WHS300 series ADCP manufactured by $R D I$ was installed, providing the $L A D C P$ technology for performing measurements [8]. The instrument settings were as follows: the depth segment size is $4 \mathrm{~m}$, the number of segments is 22, the $L A D C P$ option is enabled. Discreteness of the measurements is $1 \mathrm{~s}$. The probe submerging/elevating speed was about $0.7 \mathrm{~m} / \mathrm{s}$. The $L A D C P$ data processing was carried out taking into account the influence of the vessel hull on the magnetic compass of the instrument in the upper layer of the sea [9] and using the VMADCP and BT data [10].

Before proceeding to the discussion of the results of measurements, the preliminary comments on the system of quasi-stationary currents in the northern seas determining the physical nature of the Barents Sea PFZ should be made.

Stationary currents. The diagram of currents of the northern seas obtained from the use of surface drifters [11] shows that the North Atlantic Current, passing the Faroe-Shetland Channel, partially enters the North Sea. It carries waters mostly along the northwestern coast of Norway, as the Norwegian Atlantic Current divided into two branches around the western boundary of the Barents Sea.

One of the branches (the West Spitsbergen Current entering the Arctic Ocean through the eastern part of the Fram Strait) continues to move northward, flowing around Svalbard from the northern side and the north of Ermak plateau [12, 13] and partially returns to the Barents Sea from the north in the form of the East Spitsbergen, Bear Island and Perseus Currents [14]. Thus, the Arctic waters of the Barents Sea are originated from the North Atlantic waters, which were transformed on the way to the PFZ from the north $[15,16]$.

The second branch (the North Cape Current) goes eastward to the Barents Sea between Norway and Bear Island, carries out partially the cyclonic recycling in the water area of the Bear Island trough [3, 12 and 17]. Further it is divided into the Central and Northern branches $[2,18]$. The northern branch of the North Cape Current carries the Atlantic waters to the Hopen Deep [3], where it also performs partial cyclonic recirculation [12]. Hence, it follows that the Atlantic waters of the Barents Sea PFZ are also originated in the North Atlantic.

It is the system of quasi-stationary currents in a relatively shallow sea with a complex bottom topography that creates conditions for the formation of the PFZ separating the Atlantic (from the south) and Arctic (from the north) waters of the Barents Sea, which are different in properties [2, 15 and 16]. A more detailed differentiation of the Barents Sea by their properties is beyond the scope of the present paper [3].

The hydrological data database. The mean annual features were calculated using the BarKode database [4]. Fig. 2 shows the mean annual course of temperature ( $a$ fragment) and salinity ( $b$ fragment) at various horizons in Spitsnbergen Bank area ( $A$ point in Fig. 1). The range of the annual temperature course has its maximum at the sea surface and is about $3{ }^{\circ} \mathrm{C}$. Autumn-winter convection starts in late August - early September and penetrates into the water column at the velocity 
of $\sim 1.25 \mathrm{~m} /$ day. By early October, the temperature is almost constant throughout the depth [19], and such situation persists until the end of April. The temperature starts to increase at the end of the polar night. The maximum salinity is observed at the end of April, after which it decreases. It is well-pronounced in the upper layer of the sea and is due to ice melting and increased river runoff.
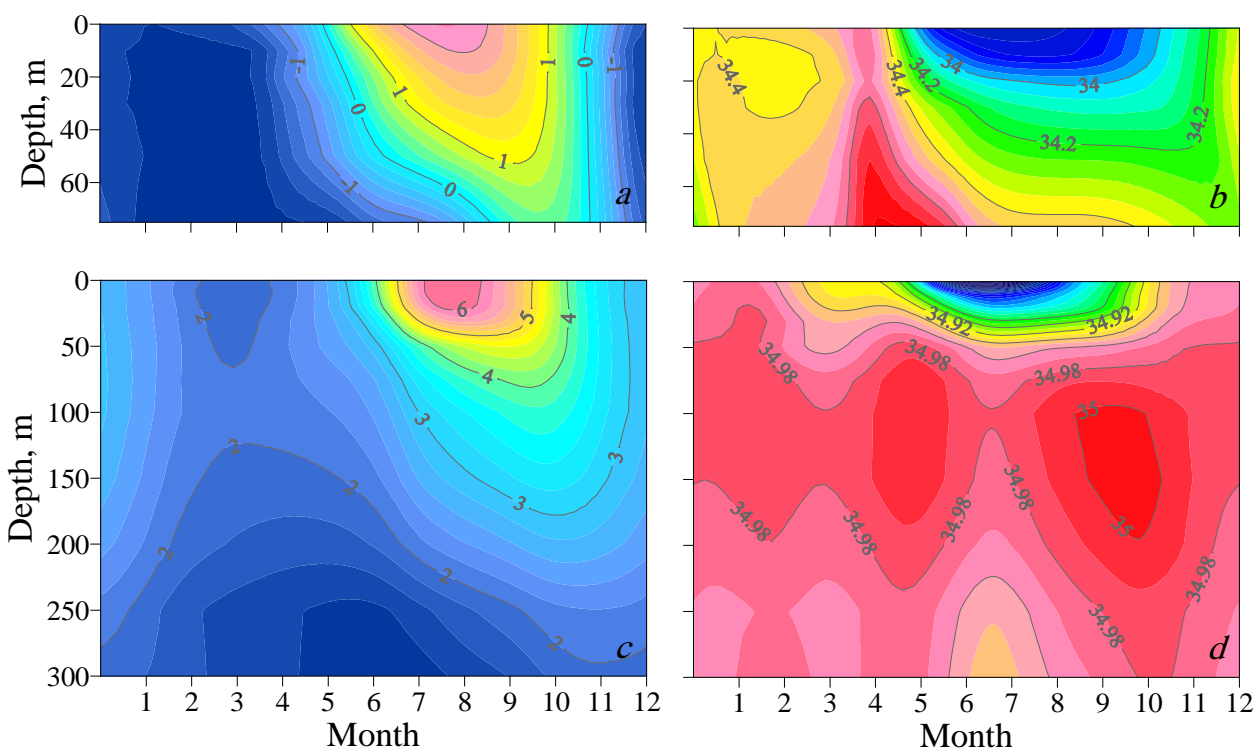

Fig. 2. Average annual characteristics according to the BarKode data: annual temperature course $\left({ }^{\circ} \mathrm{C}\right)$ A (a) and B (c) at points on different sides of the frontal zone; the annual salinity (psu) at the same points $(b, d)$

Fig. 2, $c, d$ shows similar distributions obtained for the basin of the Hopen Deep ( $B$ Point in Fig. 1). The range of the annual temperature course has a maximum value in the near-surface layer of the sea and is $\sim 6^{\circ} \mathrm{C}$. Autumn-winter convection has a similar characteristic $A$ point, but does not reach the bottom. The annual salinity course reveals a complex pattern. The salinity behavior in the upper layers is caused by the same reasons as for $A$ point. The maximum salinity in the $100-200 \mathrm{~m}$ layer is explained by the input of Atlantic waters, which is provided by the Northern branch of the North Cape Current. The salinity variability with a period of $\sim 4$ months may be due to the redistribution of flows between different branches of the quasi-stationary currents that determine the formation of the Barents Sea PFZ.

In general, the use of the historical BarKode database allows to calculate the mean annual course of hydrological characteristics in the area of the suggested research with a view to planning the measurement performance. A detailed analysis of the mean annual course is beyond the scope of the present paper and may be of particular interest for the further research [3].

Satellite data. The scanners installed on artificial satellites of the Earth are the up-to-date instrument for studying the World Ocean waters, particularly, thermal

PHYSICAL OCEANOGRAPHY NO. 2 (2017) 
frontal zones [20]. Maps of sea surface temperature (SST), calculated from satellite data, can be useful both at the preparation stage of expeditions and in the analysis of measurement results. In the polar regions the probability of obtaining highquality satellite images is relatively small due to weather conditions. The latest SST map available on the site [21] is dated June 30, 2008 and is based on MODIS/Terra satellite scanner data (4 km resolution).

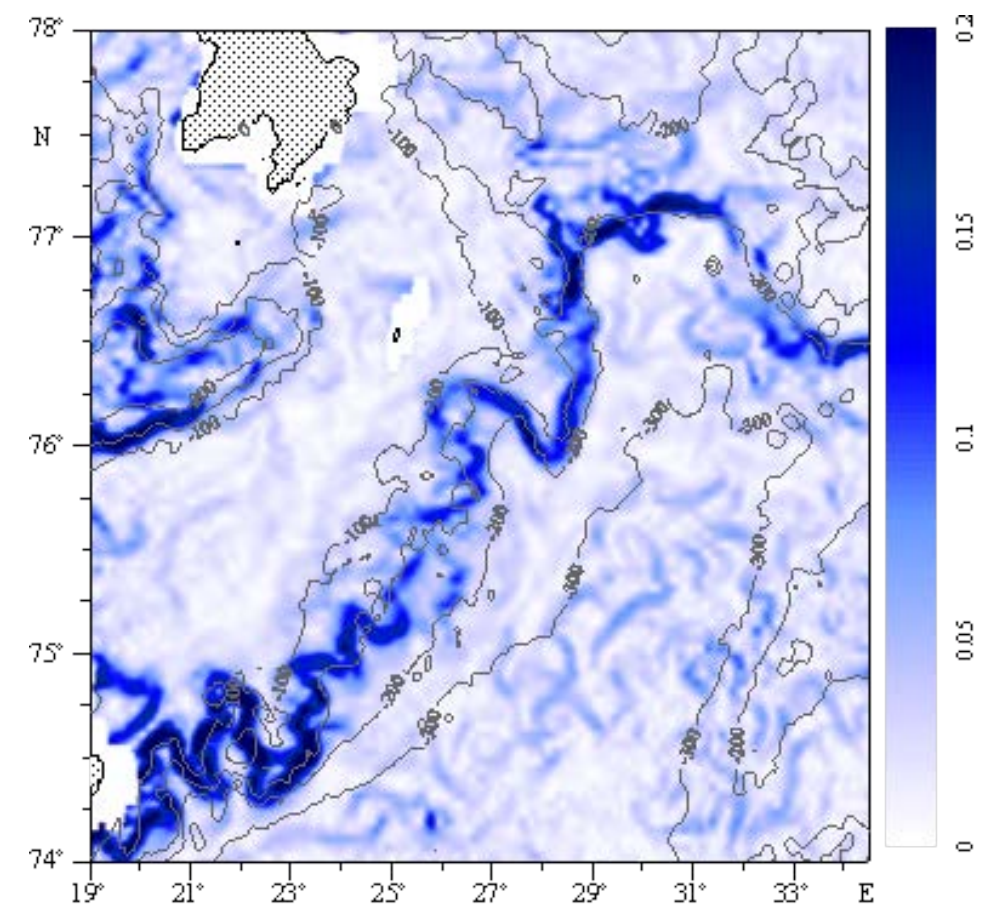

Fig. 3. Distribution of the horizontal gradient of the SST calculated from the MODIS/Terra image of June 30, 2007

Fig. 3 shows the map-calculated distribution of the SST horizontal gradient module $\left({ }^{\circ} \mathrm{C} / \mathrm{km}\right)$. Gray lines indicate the bathymetry according to ETOPO2. The position of the PFZ of the Barents Sea Western Trough is identified by an increased value of the SST gradient and to a certain extent corresponds to the existing concepts of its relation to the bottom topography features [3, 22 and 23]. The southern part of the PFZ of the Barents Sea Western Trough is most well-studied. For example, according to the results of the Bareks-92 experiment carried out in August 1992, the following data was obtained: the position of the front to $250 \mathrm{~m}$ isobath [23], its small horizontal scales are up to $3 \mathrm{~km} \mathrm{[24]} \mathrm{and} \mathrm{the} \mathrm{generation} \mathrm{of}$ non-linear wave processes caused by tides [25].

Shipboard weather station. As it has already been noted, the probability of obtaining high-quality satellite images in the area under consideration is relatively small. In addition, the satellite data resolution is insufficient to reproduce real horizontal PFZ scales. The establishment of a realistic size of the thermal front section 
in the northwestern part of the Barents Sea was one of the tasks of the NESSAR project and was solved on the basis of the shipboard weather station data (Fig. 4).
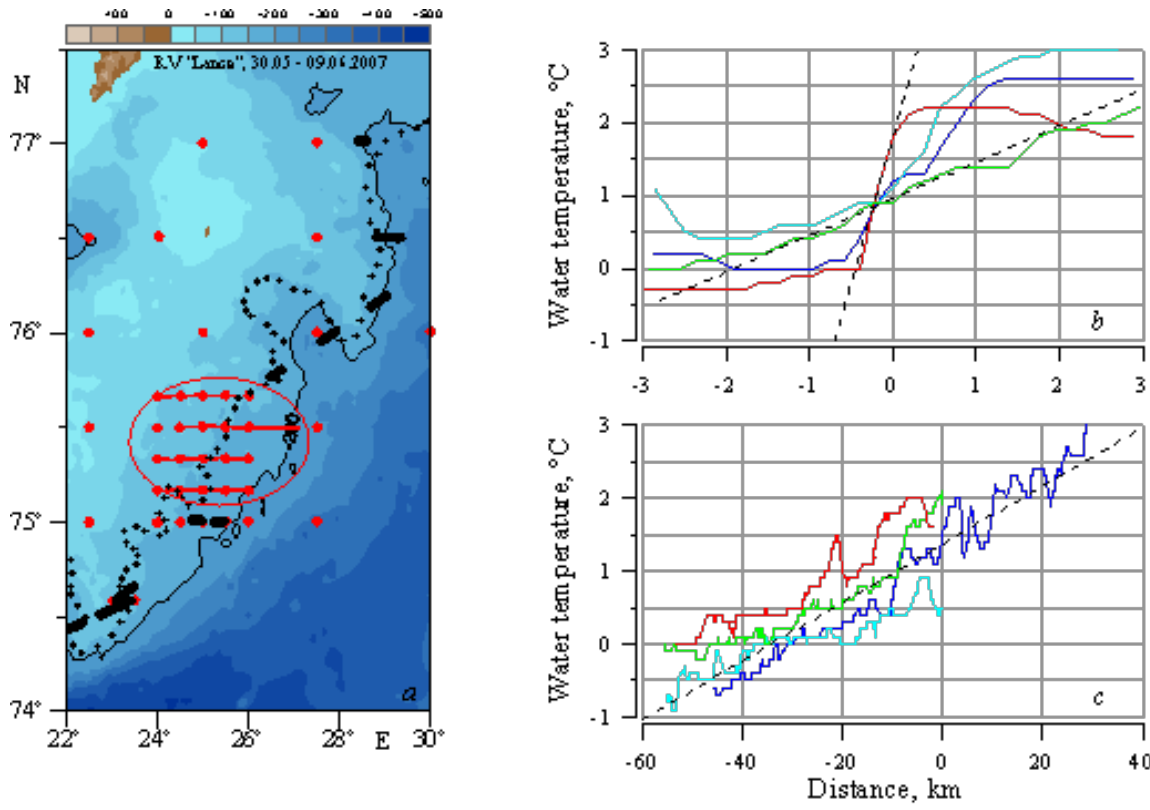

Fig. 4. The frontal section features according to the shipboard weather station data: $a$ - hydrological stations (red dots), the temperature frontal zone position (black segments), the blurring zone of the frontal section of the Atlantic and Arctic waters (red lines marked with an ellipse), the frontal zone position restored according to Fig. 3 (black crosses); $b$ - water temperature at the crossing of the frontal zone; $c$ - temperature variability in the zone of smooth division of the Arctic and Atlantic waters

In Fig. 4, $a$ the black segments show the intersections of the thermal front section registered according to the shipboard weather station data. Fig. $4, b$ shows the examples of the aforementioned intersections in the northern part of the polygon. The distance is counted off from the $200 \mathrm{~m}$ isobath. The temperature variation was $\sim 2.5^{\circ} \mathrm{C}$, which corresponds to the mean value according to the BarKode data (Fig. 2). The range of observed values of the horizontal gradient (the black dashed lines in Figure $4, b$ ) is $0.4-4^{\circ} \mathrm{C} / \mathrm{km}$, while the angle which the vessel crossed the frontal section at was not taken into account. The minimum horizontal frontal section scale of $0.5 \mathrm{~km}$ was observed on the LSO5 section (Fig. 1).

Fig. 4, $c$ shows the examples of the spatial variability of the water temperature in the micro-polygon area, where the blurring of the frontal section was observed (the area is bounded by the red ellipse in Fig. 4, $a$ ). The distance was counted off from $26^{\circ} \mathrm{E}$. The mean value of the temperature gradient was $0.04{ }^{\circ} \mathrm{C} / \mathrm{km}$ (the dashed line in Fig. 4, c). It corresponds to the background values outside the frontal zone (Fig. 3).

The crosses in Fig. 4, a show the position of the temperature gradient maximum in the PFZ area, reconstructed from the satellite image (Fig. 3). Three weeks after the position of the thermal frontal section changed relatively little, which may be a consequence of both seasonal and poorly studied mesoscale variability [2]. 
Fig. 5 shows the examples of the temperature distribution temporal variability in the vicinity of the PFZ in the expeditions of 2007 ( $a$ fragment) and 2008 ( $b$ fragment). In June 2007, the temperature gradient maximum was shifted by $14 \mathrm{~km}$ in the eastern direction within 7 days. At that, the satellite image (Fig. 3) shows the shift of the maximum temperature in the western direction by $20 \mathrm{~km} 3$ weeks after the expedition. In February 2008, there was a shift by 4 km per day in the eastern direction.
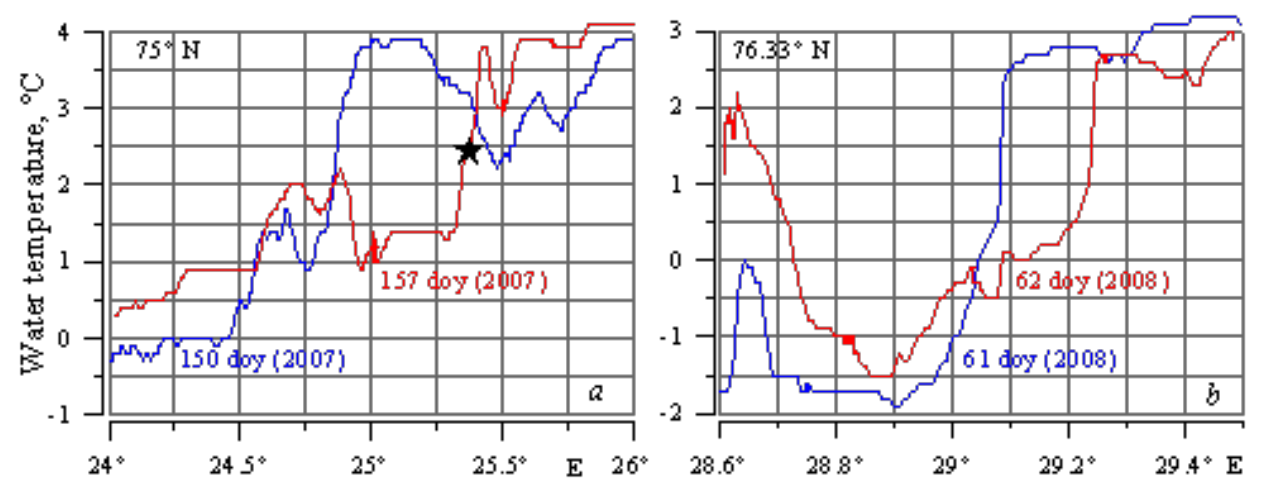

Fig. 5. Temporal variability of the frontal zone position in latitudinal sections in 2007 (a) and 2008 (b). Asterisk marks the location of the diurnal station

The materials of the expeditions do not allow to unequivocally answer the question whether the frontal section shifts are a quasi-periodic process of wave nature [2] or of a random one.

Diurnal station. Like the quasi-stationary currents, tides in the shallow Barents Sea play an important role in the formation and transformation of water masses. The interaction of tides with complex bottom topography causes an intensification of vertical mixing processes [26, 27]. Residual tidal currents above isolated underwater and surface elevations [28] create a complex picture of penetration of the Arctic water masses through the numerous straits of the northern part of the Barents Sea [16]. Note that in the area of measurement, the semidiurnal $M_{2}$ and $S_{2}$ components dominate [24].

To make the detailed manifestation of tides in the PFZ on the LSO1 section after the completion of the work on the micro-polygon, a diurnal station (Fig. 1) was carried out in the frontal section center on the $200 \mathrm{~m}$ isobath (the asterisk in Fig. 5, a). Totally, 25 synchronous profiles of temperature, salinity, conditional density, the northern $(V, \mathrm{~cm} / \mathrm{s})$ and eastern $(U, \mathrm{~cm} / \mathrm{s})$ current velocity components were obtained.

Fig. 6 shows the results of measurements. The temporal variability of the vertical structure of salinity and temperature (Fig. 6, $a$ ) is the same. In the temperature variability of the lower layer of the sea (especially, at the $160 \mathrm{~m}$ horizon), a component with a semidiurnal period is well-pronounced, in the upper layer-such a component is not manifested. The conditional density variability does not have a pronounced semidiurnal component (Fig. 6, b), while it is traced in the isopic position with a conditional density of $27.9 \mathrm{~kg} / \mathrm{m}^{3}$. The observed variation in the vertical 
structure of the hydrological parameters is a consequence of the combined effect of tidal (barotropic and baroclinic) and quasi-stable currents (Fig. 6, $c, d$ ) near the frontal section having complex bottom topography.
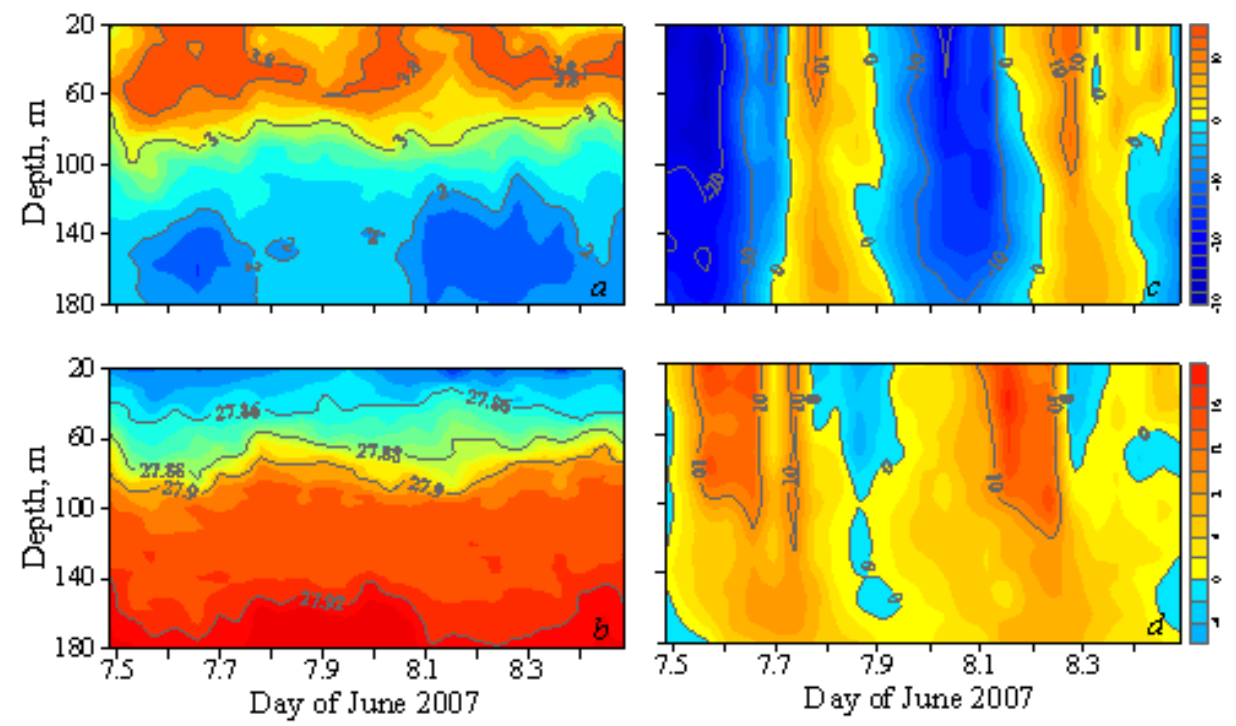

Fig. 6. The results of temperature measurements on the diurnal station $\left({ }^{\circ} \mathrm{C}\right)-a$; conditional density measurements $\left(\mathrm{kg} / \mathrm{m}^{3}\right)-b$; the eastern current velocity component $(\mathrm{cm} / \mathrm{s})-c$; the northern current velocity component $(\mathrm{cm} / \mathrm{s})-d$

Within the framework of the present paper, consideration of the results presented is limited to a discussion of the profiles averaged over horizons of various parameters of small-scale dynamics and hydrology, shown in Fig. 7.
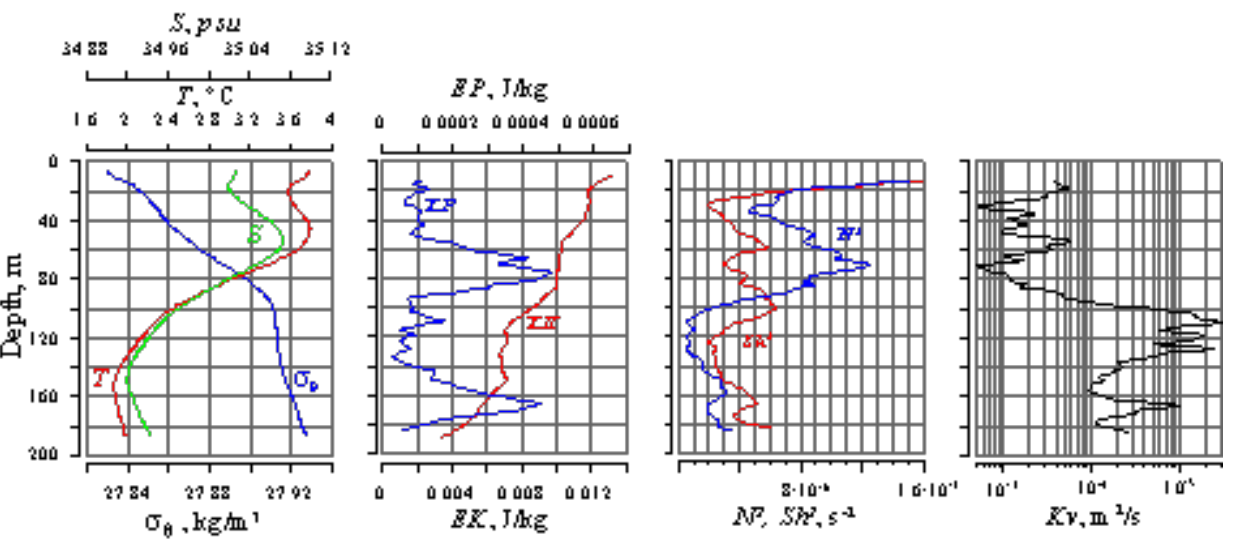

Fig. 7. The diurnal station averaged profiles of: temperature $(T)$, salinity $(S)$, conditional density $(\sigma \theta)$, available potential $(E P)$ and kinetic $(E K)$ energy, the square of the buoyancy frequency $\left(N^{2}\right)$ and the square of the vertical shift of the current velocity $\left(S h^{2}\right)$, the coefficient of vertical turbulent mixing $(K v)$

Mean temperature $(T)$, salinity $(S)$ and conditional density $\left(\sigma_{\theta}\right)$ profiles are determined by the following relations

PHYSICAL OCEANOGRAPHY NO. 2 (2017) 


$$
T=\langle T(z)\rangle=\frac{1}{25} \sum_{i=1}^{25} T_{i}(z), S=\langle S(z)\rangle=\frac{1}{25} \sum_{i=1}^{25} S_{i}(z), \sigma_{\theta}=\left\langle\sigma_{\theta}(z)\right\rangle=\frac{1}{25} \sum_{i=1}^{25} \sigma_{\theta_{i}}(z),
$$

where $T_{i}(z), S_{i}(z), \sigma_{\theta_{i}}(z)$ are corresponding profiles of individual $i^{\text {th }}$ probing; $z$ is the depth; $\langle\ldots$.$\rangle is the averaging operator for ensemble of profiles.$

The mean temperature and salinity profiles have similar features. The presence of a maximum at the horizon of $\sim 50 \mathrm{~m}$, where the waters have properties close to the properties of the Atlantic waters of the Barents Sea, is specific for them. Another feature of the mean profiles is the presence of a minimum at the horizon of $\sim 150 \mathrm{~m}$, where properties of the waters are close to arctic ones.

The mean profile of the conditional density is characterized by relatively small values of the buoyancy frequency ( $N$, rad/s), determined from the following relationship

$$
N=\sqrt{\left\langle N^{2}(z)\right\rangle}=\sqrt{\frac{g}{1000+\left\langle\sigma_{\theta}(z)\right\rangle} \frac{\partial\left\langle\sigma_{\theta}(z)\right\rangle}{\partial z}},
$$

where $g$ is the free fall acceleration of $9.82 \mathrm{~m} / \mathrm{s}^{2}$; the range of changes $N$ is 0.4 $2.2 \mathrm{cycles} / \mathrm{h}$. The highest values of the buoyancy frequency are observed in the upper 20-m layer and at the $70 \mathrm{~m}$ horizon in the local pycnocline layer.

The specific kinetic energy $(E K, \mathrm{~J} / \mathrm{kg})$ varies with depth as an almost linear function:

$$
E K(z) \approx 1.3 \cdot 10^{-2}-3.9 \cdot 10^{-5} z
$$

The given mean profile $E K$ shows that the kinetic energy enters the aquatic environment under the wind load effect and decreases with the penetration into the water column due to various dissipation mechanisms, including friction against the bottom.

The mean profile of the specific available potential energy $(E P, J / k g)$ was calculated from the following simplified relation:

$$
E P=\langle E P(z)\rangle=\frac{1}{2} \frac{g}{\left(1000+\left\langle\sigma_{\theta}(z)\right\rangle\right)} \frac{\left\langle\left(\sigma_{\theta}(z)-\left\langle\sigma_{\theta}(z)\right\rangle\right)^{2}\right\rangle}{\partial\left\langle\sigma_{\theta}(z)\right\rangle / \partial z} .
$$

The profile has two well-pronounced maxima: the first one is in the local pycnocline layer at the horizon of $\sim 80 \mathrm{~m}$, the second - at the $\sim 160 \mathrm{~m}$ horizon, where a relatively small increase in the buoyancy frequency is observed. In the entire water column $E K$ is over an order greater than $E P$.

The mean profile of the square of the vertical shift of current velocity $\left(S h^{2}, s^{-2}\right)$ was calculated from the following relation:

$$
S h^{2}=\left\langle S h^{2}(z)\right\rangle=\left\langle\left(\frac{\Delta U}{\Delta h}\right)^{2}+\left(\frac{\Delta V}{\Delta h}\right)^{2}\right\rangle,
$$


where $\Delta h=4 \mathrm{~m}$ is the depth increment. In the upper $20-30 \mathrm{~m}$ layer, higher values of the shift are observed. It is mainly a consequence of the spatiotemporal variability of the wind load on the sea surface. There is an insignificant minimum of shift in the local pycnocline layer $(70 \mathrm{~m})$, at the $100 \mathrm{~m}$ horizon - its local maximum. Below $120 \mathrm{~m}$, there is a relative increase in the shift observed as it approaches the bottom.

Synchronous profiles of the current velocity and buoyancy frequency shifts allow to estimate the coefficient of vertical turbulent mixing $\left(K v, \mathrm{~m}^{2} / \mathrm{s}\right)$. The basis for the most models uniting small-scale features of hydrophysical fields with vertical mixing parameters is the assumption that the kinetic energy of internal waves is equal in spectrum to the region of small scales and to the dissipation rate of kinetic turbulent energy [29]. For the $K v$ estimation, the G89 model [30] was used in the form as presented in [31], taking into account the geographic location of the measurement area $\left(k_{\text {geogr }}=0.31^{-1}\right)[26]$ :

$$
K v(z)=5 \cdot 10^{-6} \frac{\left\langle\operatorname{Sh}^{4}(z)\right\rangle}{\left\langle N^{4}(z)\right\rangle} k_{\text {geogr }} .
$$

The $K v(z)$ mean profile is characterized by the values of $\sim 10^{-5} \mathrm{~m}^{2} / \mathrm{s}$ in the upper $100 \mathrm{~m}$ layer and a well-pronounced minimum at $70 \mathrm{~m}$ horizon, which corresponds to the maximum. In the $100-140 \mathrm{~m}$ layer the coefficient increases by almost two orders, up to $10^{-3} \mathrm{~m}^{2} / \mathrm{s}$, drops to $10^{-4} \mathrm{~m}^{2} / \mathrm{s}$ at the $150 \mathrm{~m}$ horizon and rises as it approaches the bottom. The behavior with the depth obtained from small-scale measurements is in good agreement with the results of microstructural measurements carried out in the Storfjordrenna area in September 2003 on the $\sim 200 \mathrm{~m}$ isobath [26]. A detailed discussion of the problem of estimation of the vertical turbulent mixing parameters based on the small-scale measurements goes beyond the scope of the present paper [26, 32 and 33].

Currents. The identification of quasi-stationary currents in the Barents Sea based on the data of in situ measurements is a problematic issue, since their velocities are comparable with the velocities of tidal water movements. In Fig. 8, the eastern ( $a$ fragment) and northern ( $b$ fragment) current velocity components averaged over the measurement layer are shown by solid lines, obtained from the $V M A D C P$ data during the diurnal station. Dashed lines mark the velocities of tidal movements calculated by the AOTIM5 model [34] for the two components $M_{2}, S_{2}$. The mean values of $U$ and $V$ are -2 and $5 \mathrm{~cm} / \mathrm{s}$, respectively. The tidal velocity amplitude was $10 \mathrm{~cm} / \mathrm{s}$ for the eastern component and $5 \mathrm{~cm} / \mathrm{s}$ for the northern one. Further data on the currents is given below excluding the tides:

$$
U=U_{\text {measured }}-U_{\text {AOTIM 5:M }}, S_{2}, \quad V=V_{\text {measured }}-V_{\text {AOTIM } 5: M_{2}, S_{2}} .
$$



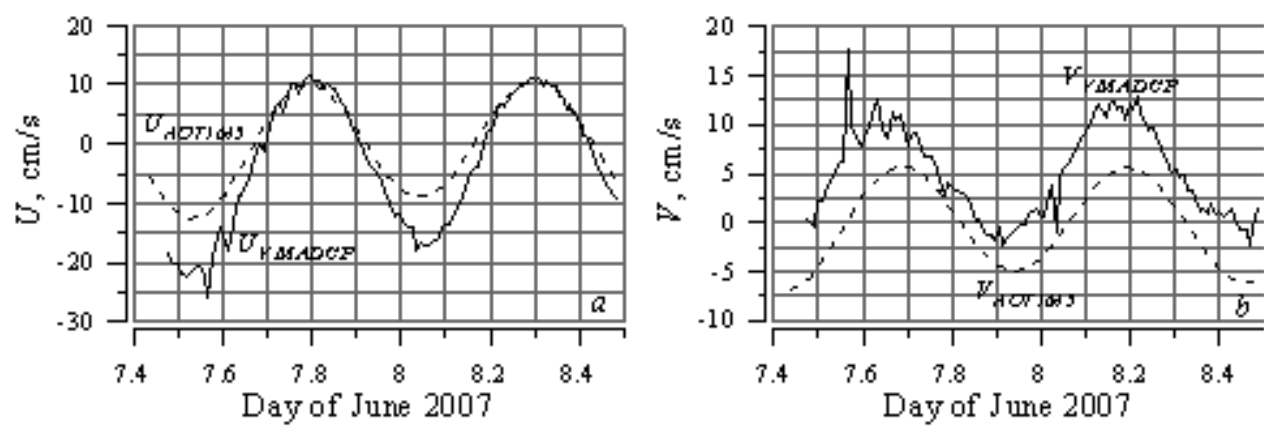

Fig. 8. Tidal currents: $a$ is the eastern current velocity component (solid line) and the tidal component $M_{2}, S_{2}$ (dashed line) calculated on the basis of the AOTIM5 model; $b$ - the northern current velocity component (solid line) and the tidal component $M_{2}, S_{2}$ (dashed line) calculated on the basis of the AOTIM5 model

The quasi-stationary flow along the western edge of the Hopen Deep is determined in the results of both laboratory [35] and numerical experiments [36]. At the same time, the calculations on geostrophic relationships do not reveal it [18].
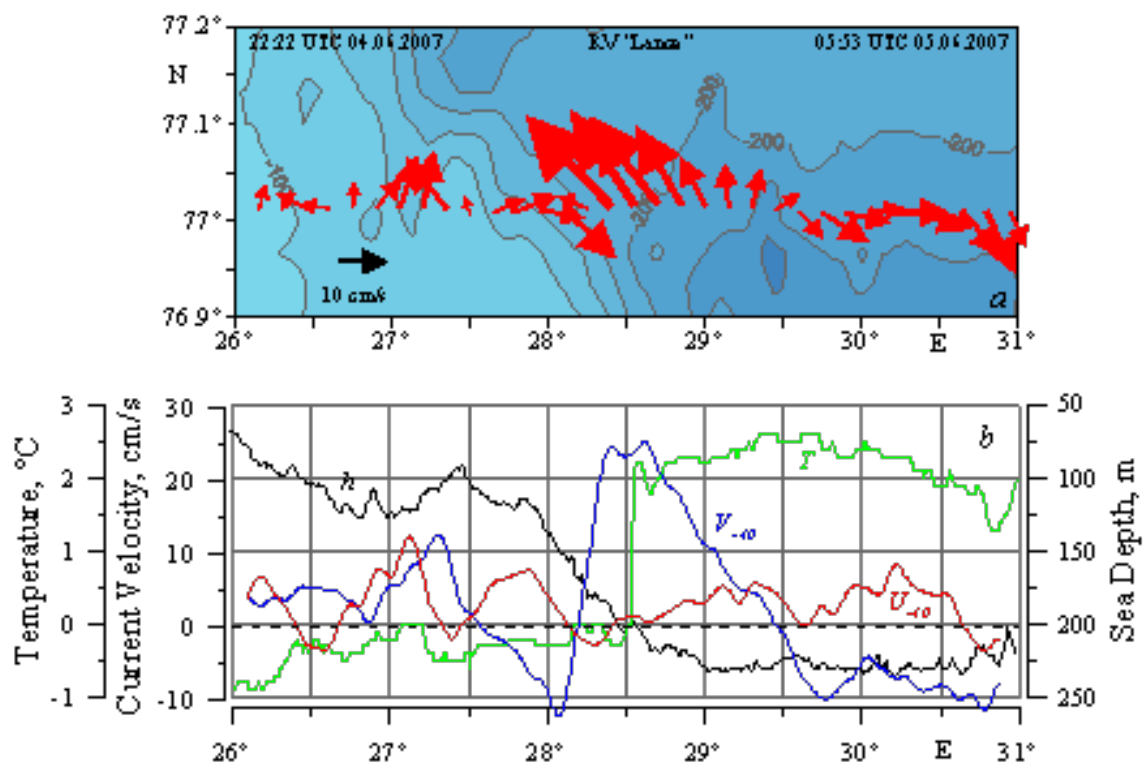

Fig. 9. The results of measurements on the LS05 section: the velocities of currrent (averaged over the $20-80 \mathrm{~m}$ layer) in vector form $-a$; the sea depths $-h$, the sea surface temperatures $-T$, the current velocity projections $-U_{-40}, V_{-40}-b$

In the expedition this current was most clearly manifested on the LSO5 northern section. In Fig. 9, $a$ the current velocity distribution is represented in vector form (red arrows). Fig. 9, $b$ shows the dependencies of various parameters on the longitude: the black line - the sea depth; the green line - the water temperature in the near-surface layer; the current velocity projection $\left(U_{-40}, V_{-40}\right)$ on axes of the coordinate system, deployed relative to the geographic one by $40^{\circ}$ counterclockwise, is indicated by the red and blue lines, respectively. In the vicinity of the 46 
$200 \mathrm{~m}$ isobath, the frontal section and the core of the jet stream are revealed. On the west side, the value of the Kibel - Rossby number reaches two, which can be considered as a sign of barotropic instability of the current [37]. The observed $\mathrm{U}_{-40}$ variations with $\sim 5 \mathrm{~cm} / \mathrm{s}$ amplitude $\sim 20 \mathrm{~km}$ period can be considered as a result of such instability, however, under a condition of the complex bottom topography they may be of a different origin.

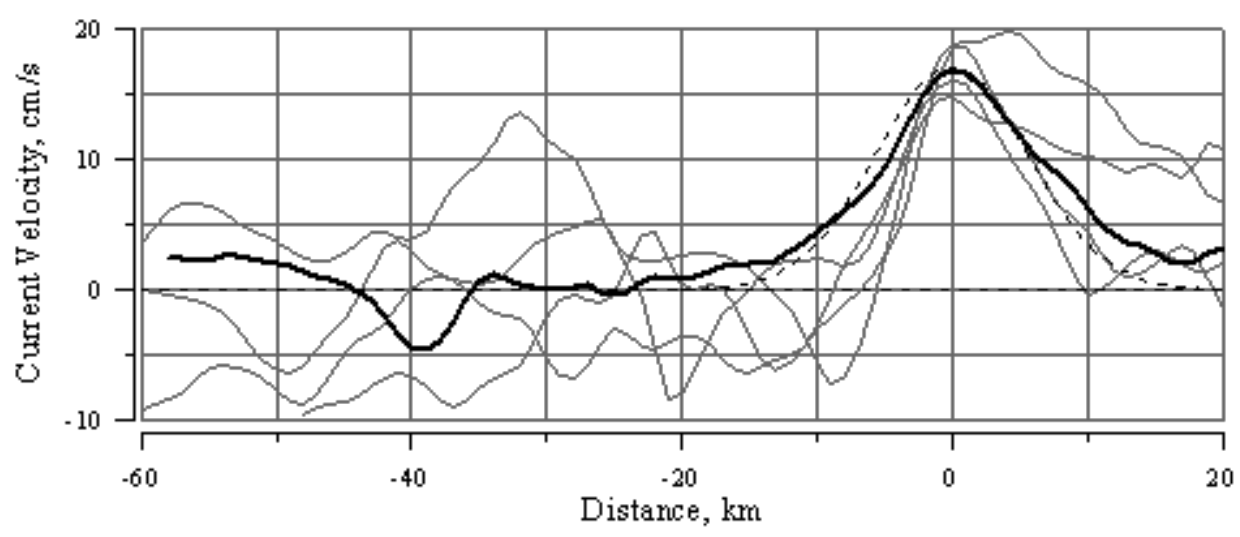

Fig. 10. The northern component of the current velocity as a function of the distance on the separate sections (gray lines) and its averaged values (thick black line). The distance is measured from the frontal section center

At the time of the research performance, the Rossby deformation radius was about $2.5 \mathrm{~km}$ in the PFZ area. Both mesoscale processes and tides mask the quasistationary currents in the measurement data. In the summer expeditions of 2007, 15 crossings of the frontal zone were carried out. In Fig. 10 the gray lines show the dependence of the northern component of the current velocity on the distance to the water parting on the separate sections. The thick solid line marks the distribution of the northern component of the current velocity averaged over all intersections. The dashed line is an approximating function $V(x)=17 \exp \left(-x^{2} / 8^{2}\right)$, where $x$ is the distance $(\mathrm{km}) ; V$ is the velocity $(\mathrm{cm} / \mathrm{s})$. If we formally consider $8 \mathrm{~km}$ as the mean effective width of the jet stream, it will amount to more than three Rossby deformation radii.

Conclusion. Three following sources of information were used in the present paper: the historical database of hydrological data, satellite images and contact observations. Such complex data allowed the expeditious planning of the execution of expeditionary studies and to analyze the features of the PFZ structure witin a wide range of spatial scales.

The intra-annual variability of water salinity in the Hopen Deep calculated based on the BarKode database, revealed the presence of variations with a period of four months. They are presumably due to the natural oscillations in a system of quasi-stationary currents forming the Barents Sea PFZ.

Satellite maps of sea surface temperature permitted to localize the frontal section position in the entire north-western area of the Barents Sea and reveal some incon- 
sistencies with earlier published works, which may be due to the seasonal variability of the PFZ.

Contact measurements carried out in a seaway and at the drift stations allowed to establish the specific horizontal and vertical scales of the current velocity field variability and hydrological parameters in the PFZ area.

Taken as a whole, the improvement of methods for the aquatic environment condition monitoring and the complex analysis of different kinds of data create favorable conditions for a deeper understanding of the role of various-scale processes in the formation and evolution of the frontal zones of the World Ocean.

Acknowledgements. We express our profound gratitude to the crews of $\mathrm{R} / \mathrm{V}$ Lance of the Norwegian Polar Institute, who rendered invaluable assistance in carrying out the measurements.

The data of contact measurements was obtained and processed within the framework of NESSAR 2007 - 2009, supported by RCN. The work was carried out within the framework of the State Order No. 0827-2014-0011 Research of the regularities of changes in the condition of the marine environment on the basis of operational observations and data of the system of diagnosis, prognosis and reanalysis of the condition of marine areas (Operational Oceanography).

\section{REFERENCES}

1. Fedorov, K.N., 1983. Fizicheskaya Priroda i Struktura Okeanicheskikh Frontov [The Physical Nature and Structure of Oceanic Fronts]”. Leningrad: Gidrometeoizdat, 296 p. (in Russian).

2. Rodionov, V.B. and Kostyanoy, A.G., 1998. Okeanicheskie Fronty Morey SeveroEvropeyskogo Basseyna [Oceanic Fronts of the North European Basin Seas]. Moscow: GEOS, 290 p. (in Russian).

3. Harris, C.L., Plueddemann, A.J. and Gawarkiewicz, G.G., 1998. Water Mass Distribution and Polar Front Structure in the Western Barents Sea. J. Geophys. Res., [e-journal] 103 (C2), pp. 2905-2917. doi:10.1029/97JC02790

4. Golubev, V.A. and Zuev, A.N., 1999. Barents and Kara Seas Oceanographic Data Base (BarKode) / C. Oelke, ed. IACPO Informal Report No. 5. The International ACSYS/CLIC Project Office, Bremerhaven, PANGAEA. doi:10013/epic.28428

5. Joyce, T.M., 1989. On In Situ “Calibration” of Shipboard ADCPs. J. Atmos. Oceanic Technol., [e-journal] 6(1), pp. 169-172. https://doi.org/10.1175/1520-0426(1989)006<0169:OISOSA>2.0.CO;2

6. Pollard, R. and Read, J., 1989. A Method for Calibrating Shipmounted Acoustic Doppler Profilers and the Limitations of Gyro Compasses. J. Atmos. Oceanic Technol., [e-journal] 6(6), pp. 859-865. https://doi.org/10.1175/1520-0426(1989)006<0859:AMFCSA >2.0.CO;2

7. Morozov, A.N. and Pavlov, V.K., 2012. Korrektsiya Dannykh VMADCP [VMADCP - Data Corrections]. In: Sistemy Kontrolya Okruzhayushchey Sredy [Environmental Control Systems]. Sevastopol: ECOSI-Gidrofizika. Iss. 18, pp. 7-10 (in Russian).

8. Firing, E. and Gordon, R.L., 1990. Deep Ocean Acoustic Doppler Current Profiling. In: Proc. IEEE 4th Working Conf. on Current Measurements. MD, IEEE, pp. 192-201. doi:10.1109/CURM.1990.110905

9. Morozov, A.N. and Lemeshko, E.M., 2006. Methodical Aspects of the Application of Acoustic Doppler Current Profilers in the Black Sea. Physical Oceanography, [e-journal] 16(4), pp. 216-233. doi:10.1007/s11110-006-0027-8 
10. Visbeck, M., 2002. Deep Velocity Profiling Using Lowered Acoustic Doppler Current Profilers: Bottom Track and Inverse Solutions. Atmos. Oceanic Techn., [e-journal] 19 (5), pp. $794-$ 807. https://doi.org/10.1175/1520-0426(2002)019<0794:DVPULA >2.0.CO;2

11. Poulain, P.-M., Warn-Varnas, A. and Niiler, P.P., 1996. Near-Surface Circulation of the Nordic Seas as Measured by Lagrangian Drifters. J. Geophys. Res., [e-journal] 101(C8), pp. 1823718258. doi:10.1029/96JC00506

12. Furevik, T., 2001. Annual and Interannual Variability of Atlantic Water Temperatures in the Norwegian and Barents Seas: 1980-1996. Deep-Sea Res. I, [e-journal] 48(2), pp. 383-404. https://doi.org/10.1016/S0967-0637(00)00050-9

13. Cokelet, E.D., Tervalon, N. and Bellingham, J.G., 2008. Hydrography of the West Spitsbergen Current, Svalbard Branch: Autumn 2001. J. Geophys. Res., [e-journal] 113(C1), C01006, 16 p. doi:10.1029/2007JC004150

14. Tantsyura, A.I., 1973. O Sezonnykh Izmeneniyakh Techeniy Barentseva Morya [On the Seasonal Variations in the Barents Sea Currents]. In: Trudy PINRO [Proceedings of the Polar Research Institute of Marine Fisheries and Oceanography]. Murmansk: PINRO. Iss. 34, pp. 108112 (in Russian).

15. Loeng, H., 1991. Features of the Physical Oceanographic Conditions of the Barents Sea. Polar Res., [e-journal] 10(1), pp. 5-18. http://dx.doi.org/10.3402/polar.v10i1.6723

16. Løyning, T.B., 2001. Hydrography in the North-western Barents Sea, July-August 1996. Polar Res., [e-journal] 20(1), pp. 1-11. http://dx.doi.org/10.3402/polar.v20i1.6495

17. Skagseth, Ø., 2008. Recirculation of Atlantic Water in the Western Barents Sea. Geophys. Res. Lett., [e-journal] 35(11), L11606. doi:10.1029/2008GL033785

18. Kushnir, V.M., Hansen, E., Petrenko, L.A., Pavlov, V.K., Morozov, A.N., Stanichnyi, S.V. and Fedorov, S.V., 2007. Currents and Turbulent Diffusion in the Bottom Boundary Layer of the Barents Sea. Physical Oceanography, [e-journal] 17(5), pp. 278-295. doi:10.1007/s11110-0070022-8

19. Kushnir, V.M., Hansen, E., Pavlov, V.K. and Morozov, A.N., 2003. Thermochaline Convection in the Edge-Ice Zone in the Barents Sea to the East of Spitsbergen. Physical Oceanography, [e-journal] 13(6), pp. 361-374. doi:10.1023/B:POCE.0000013233.69589.d1

20. Aleksanin, A.I. and Kim, V., 2016. Sea-Surface Temperature Chart Enhancement in Frontal Zones. Izv. Atmos. Ocean. Phys. [e-journal] 52(9), pp. 1162-1171. doi:10.1134/S0001433816090024

21. PODAAC. Physical Oceanography Distributed Active Archive Center. [online] Available at: https://podaac.jpl.nasa.gov [Accessed 07 November 2016].

22. Johannessen, O.M. and Foster, L.A., 1978. A Note on the Topographically Controlled Oceanic Polar Front in the Barents Sea. J. Geophys. Res., [e-journal] 83(C9), pp. 4567-4571. doi:10.1029/JC083iC09p04567

23. Gawarkiewicz, G. and Plueddemann, A.J., 1995. Topographic Control of Thermohaline Frontal Structure in the Barents Sea Polar Front on the South Flank of Spitsbergen Bank. J. Geophys. Res., [e-journal] 100(C3), pp. 4509-4524. doi:10.1029/94JC02427

24. Parsons, A.R., Bourke, R.H., Muench, R.D., Chiu, C.-S., Lynch, J.F., Miller, J.H., Plueddemann A.J. and Pawlowicz, R. 1996. The Barents Sea Polar Front in Summer. J. Geophys. Res., [e-journal] 101(C6), pp. 14201-14221. doi:10.1029/96JC00119

25. Vlasenko, V., Stashchuk, N., Hutter, K. and Sabinin, K., 2003. Nonlinear Internal Waves Forced by Tides near the Critical Latitude. Deep-Sea Res. I, [e-journal] 50(3), pp. 317-338. https://doi.org/10.1016/S0967-0637(03)00018-9

26. Fer, I., 2006. Scaling Turbulent Dissipation in an Arctic Fjord. Deep-Sea Res. II, [e-journal] 53(1-2), pp. 77-95. doi:10.1016/j.dsr2.2006.01.003

27. Sundfjord, A., Fer, I., Kasajima, Y. and Svendsen, H., 2007. Observations of Turbulent Mixing and Hydrography in the Marginal Ice Zone of the Barents Sea. J. Geophys. Res., [e-journal] 112(C5), C05008, 23 p. doi:10.1029/2006JC003524

28. Kowalik, Z. and Proshutinsky, A.Y., 1995. Topographic Enhancement of Tidal Motion in the Western Barents Sea. J. Geophys. Res., [e-journal] 100(C2), pp. 2613-2637. doi:10.1029/94JC02838

PHYSICAL OCEANOGRAPHY NO. 2 (2017) 
29. Gregg, M.C., Sanford, T.B. and Winkel, D.P., 2003. Reduced Mixing from the Breaking of Internal Waves in Equatorial Waters. Nature, [e-journal] 422, pp. 513-515. doi:10.1038/nature01507

30. Gregg, M.C., 1989. Scaling Turbulent Dissipation in the Thermocline. J. Geophys. Res., [e-journal] 94(C7), pp. 9686-9698. doi:10.1029/JC094iC07p09686

31. Cisewski, B., Strass, V.H. and Prandke, H., 2005. Upper-Ocean Vertical Mixing in the Antarctic Polar Front Zone. Deep-Sea Res., [e-journal] 52(9-10), pp. 1087-1108. https://doi.org/10.1016/j.dsr2.2005.01.010

32. Forryan, A., Martin, A.P., Srokosz, M.A., Popova, E.E., Painter, S.C. and Renner, H.H., 2013. A New Observationally Motivated Richardson Number Based Mixing Parametrization for Oceanic Mesoscale Flow. J. Geophys. Res., 2013, [e-journal] 118(3), pp. 1405-1419. doi:10.1002/jgrc.20108

33. Morozov, A.N. and Lemeshko, E.M., 2014. Otsenka Vertikal'noy Turbulentnoy Diffuzii po Dannym CTD/LADCP-Izmereniy v Severo-zapadnoy Chasti Chernogo Morya v Mae 2004 Goda [Evaluation of Vertical Turbulent Diffusion from CTD/LADCP Measurements in the Northwestern Part of the Black Sea in May 2004]. Morskoy Gidrofizicheskiy Zhurnal, (1), pp. 58-67 (in Russian).

34. Padman, L. and Erofeeva, S., 2004. A Barotropic Inverse Tidal Model for the Arctic Ocean. Geophys. Res. Lett., [e-journal] 31(2), L02303. doi:10.1029/2003GL019003

35. McClimans, T.A. and Nilsen, J.H., 1993. Laboratory Simulation of the Ocean Currents in the Barents Sea. Dyn. Atmos. Oceans, [e-journal] 19(1-4), pp. 3-25. https://doi.org/10.1016/03770265(93)90030-B

36. Maslowski, W., Marble, D., Walczowski, W., Schauer, U., Clement, J.L. and Semtner, A., 2004. On Climatological Mass, Heat, and Salt Transports through the Barents Sea and Fram Strait from a Pan-Arctic Coupled Ice-Ocean Model Simulation. J. Geophys. Res., [e-journal] 109(C3), C03032, 16 p. doi:10.1029/2001JC001039

37. Pedley, T.J., 1969. On the Stability of Viscous Flow in a Rapidly Rotating Pipe”. J. Fluid Mech., [e-journal] 35(1), pp. 97-115. doi:10.1017/S002211206900098X 